\title{
DYNAMICS OF BODY COMPOSITION AND BODY IMAGE OF SEDENTARY WORKING WOMEN WHO ATTEND ZUMBA OR FUNCTIONAL TRAINING PROGRAMS: PILOT STUDY
}

\author{
Ernesta Aukštuolytė, Vilma Mauricienė, Algė Daunoravičienė, \\ Giedrè Knispelytė, Kristina Berškienè \\ Lithuanian University of Health Sciences, Kaunas, Lithuania
}

\begin{abstract}
Background. The aim of the study was to evaluate dynamics of body composition and body image in women who perform sedentary work and are attending Zumba or functional training programs.

Methods. There were 31 women taking part in this study. They attended Zumba $(n=16)$ or functional training $(n=15)$ programs. All participants were asked to fill in Body Image Scale and Body Shape Questionnaire. Participants' body composition was evaluated by measuring skinfold thickness with a calliper. All measurements were made twice: before and after eight weeks.

Results. No statistically significant changes of body composition were found in Zumba and in functional training groups. The results showed that women became more satisfied with their bodies after the functional training program.

Conclusion. Body composition did not change significantly after eight weeks of Zumba or functional training, however the reduction of body dissatisfaction was observed after the functional training program.
\end{abstract}

Keywords: body dissatisfaction, fat mass, fat free mass.

\section{INTRODUCTION}

$\mathrm{R}$ ecent research has shown that office workers spend between $66-82 \%$ of their work hours sedentarily (Bergman, Boraxbekk, Wennberg, Sorlin, \& Olsson, 2015). Low energy expenditure due to lack of activities during sedentary work is a main reason for the increase in overweight and obesity (Church et al., 2011).

Overweight and obesity have become a major and growing nutritional problem in today's modern world (Ribeiro-Silva et al., 2017). According to the World Health Organization (WHO), nearly 40\% eighteen-year-olds and older population in the world were overweight and $13 \%$ adults were obese. The mortality rate from obesity is higher than from famine in the world. Obesity is associated with an increased risk of type 2 diabetes, hypertension, hyperlipidemia, sleep apnea, osteoarthritis and other conditions (Williams, Mesidor, Winters, Dubbert, \& Wyatt, 2015). Over the past decade, various therapeutic ways have been sought to help solve this problem (Abdelaal, le Roux, \& Docherty, 2017).

Concerns about the appearance of the body are relevant not only in adolescence, but also in all stages of woman's age. It is not a consequence of modern culture, this was a relevant issue throughout history and the perception of the individual's beauty has changed to this day. Since the 1960s the slender body of a woman and the muscular body of a man have started being ideal (Garrusi \& Baneshi, 2017). Today, the aspiration of many women is not only a slender body, but an athletic body, which is even more challenging for women. 
Prevailing healthy lifestyle cult also influences the attitude of one's own body in these days. The body image defines the physical perception of the body and the emotional response to it. Body image is a complex somatic and mental dimension. In Western countries, the extremely lean body's ideology increases the body dissatisfaction, the use of drastic weight loss means and eating disorders (Sakalauskaitè \& Tutkuvienè, 2009). Disordered eating and body shame may be detected among athletes, exercisers and sedentary women despite the physical activity level. Research has shown that there were no significant differences in disordered eating, body dissatisfaction, self-esteem and fluid manipulation - related behaviour among athletes, exercisers and sedentary female students (Jankauskiene \& Pajaujiene, 2012). Jankauskiene, Pajaujiené, and Mickūniené (2010) have found that in order to meet social expectations, the risk of eating disorder increases regardless of the body mass index. Another research has shown that physical activity experience is related with higher body shape satisfaction (Jankauskiene, Kardelis, \& Pajaujiene, 2005). Women look for different ways to improve their appearance to meet their appearance standards (Garrusi \& Baneshi, 2017).

One of the most popular aerobic physical activities is Zumba training (Luettgen, Foster, Doberstein, Mikat, \& Porcari, 2012). Modern Zumba workout choreography includes Salsa, Merengo, hip-hop, Samba, Mambo dance moves, aerobic steps, squats, split squats and other exercises. Latin music rhythm sounds during the Zumba sessions.

Functional workout is not a new concept. Functional training is designed to enhance dayto-day activities, recreational activities and/or sports activities. The object of this training is the neuromuscular system, where movements are trained (muscle groups and nervous system), not only muscles (Beckham \& Harper, 2010). Functional workouts are effective in improving muscle strength, balance, mobility, and the quality of daily movements. Functional training affects the muscles in coordinated, multi-axial movements and involves multiple joints, dynamic tasks, consistent level of support surface to improve function. It is said that functional training is a purposeful training method because the function itself is already a goal. The principle of functional training is the specificity of the workout - a specific movement is trained to maximize its performance. In other words, the desired goal is better if workout is closer to it. In order to improve day-to-day performance, the exercise program should include similar movements and patterns of performance as in daily activities (Liu, Shiroy, Jones, \& Clark, 2014).

The aim of the study was to evaluate dynamics of body composition and body image in women who perform sedentary work and attend Zumba or functional training programs.

\section{METHODS}

Participants. There were 31 sedentary women taking part in this study who attended functional $(n=15)$ or Zumba training $(n=16)$ programs. The inclusion criteria of participants were: young age (up to 44 years), sedentary work, attendance of functional or Zumba training, but not any other physical activities. Mean age of women in functional training group was 34.7 (22-44) years, in Zumba group - $36.4(26-44)$ years. The participants of the study attended functional training sessions or Zumba training sessions which were held two times per week, for eight weeks. The duration of one session was $60 \mathrm{~min}$. All measurements were made twice: before and after eight weeks. All participants were informed about the aim of the study, research procedures, requirements and benefits. Ethics approval No. BEC-1R(M)-92 was granted from the Ethical Committee of Lithuanian University of Health Sciences.

Assessment of body composition. Body composition was evaluated by measuring skinfold thickness with a calliper at four body sites - triceps, abdominal, supraspinale and thigh (Jackson, Pollock, \& Ward, 1980). These skinfold measurements were used for percent body fat, absolute fat mass, fat free mass and fat free mass index calculation. The body weight of participants was measured using electronic scales with measurement accuracy of $100 \mathrm{~g}$.

Assessment of body image. Figure rating scale was used for body image assessment (Pruis, \& Janowsky, 2010) The permission to use this scale was obtained from the scale authors. Figure rating scale comprises a series of nine male or female figure drawings of increasing body size. In this figure rating scale, the participants of the research were asked to select from 9 female body figures of increasing size (labelled 1-9) that best resembled their current body size and desired body size. In this way subjective self-evaluation of the participants, the real and desired body image, were 
observed. By subtracting the ideal number of body image from the real body image, we got an ideal body image gap from the real. A greater difference indicates greater dissatisfaction with participant's body.

Also Cooper, Taylor, Cooper, and Fairburn's (1987) Body Shape Questionnaire (BSQ) was used to evaluate the signs of dissatisfaction with body image. We used a shortened form of the questionnaire consisting of 16 questions. The Lithuanian version of the body shape questionnaire was received from the author and the authors of the Body shape questionnaire gave the permission to use this questionnaire. The purpose of the questionnaire is to determine the fear of the subjects to gain weight, self-evaluation dependence on the appearance of the body, the desire to lose weight and dissatisfaction with their own body. Reliability of the shortened questionnaire (Cronbach $\alpha$ ) was .87 .

Statistical analysis. Data analysis was performed using "SPSS 21.0 for Windows" and "Microsoft Office Excel 2013". Nonparametric tests were used to compare samples: the Wilcoxon criteria were used to compare two dependent samples and the Man-Witney-Wiloxon criteria were used for comparing two independent samples. The data are presented as a median (the minimum value - the maximum value, the average). Statistical significance was set at $p<.05$.

\section{RESULTS}

Changes in body composition parameters. There was no difference between the two groups before attending Zumba and functional training programs in body weight $(U=106, p=.6)$, percent body fat $(U=98, p=.4)$, absolute fat mass $(U=$ $86, p=.18)$, fat free mass $(U=115, p=.86)$ or fat free mass index $(U=99, p=.42)$. After Zumba and functional training programs we did not observe statistically significant changes of body composition parameters, only the tendency of the body weight, percent body fat and absolute body fat decrease were estimated (Table 1).

Table. Changes in body composition parameters after Zumba and Functional training programs

\begin{tabular}{|c|c|c|c|}
\hline $\begin{array}{c}\text { Training } \\
\text { programs }\end{array}$ & Before & After & Criteria value; $p$ value \\
\hline \multicolumn{4}{|c|}{ Body weight (kg) } \\
\hline Zumba & $67.35(55.4-87.2,68.31)$ & $67(55.9-86,67.9)$ & $\mathrm{Z}=-1.78, p=.07$ \\
\hline $\begin{array}{c}\text { Functional } \\
\text { training }\end{array}$ & $66.7(52.8-80,66.36)$ & $66.3(52.9-79.5,66.2)$ & $\mathrm{Z}=-1.51, p=.13$ \\
\hline \multicolumn{4}{|c|}{ Body mass index } \\
\hline Zumba & $24.14(21.75-31.21,25.39)$ & $24.12(21.6-31.09 ; 25.24)$ & $\mathrm{Z}=-1.76, p=.08$ \\
\hline $\begin{array}{c}\text { Functional } \\
\text { training }\end{array}$ & $23.49(19.63-29.38,24.06)$ & $23.7(19.66-29.2 ; 24)$ & $Z=-1.5, p=.13$ \\
\hline \multicolumn{4}{|c|}{ Percent body fat (\%) } \\
\hline Zumba & $26.97(21.95-39.28,28.91)$ & $27.25(21.15-39,27.71)$ & $\mathrm{Z}=-1.47, p=.14$ \\
\hline $\begin{array}{c}\text { Functional } \\
\text { training }\end{array}$ & $26.92(15.78-34.19,26.42)$ & $27.1(16.59-33.52,26.25)$ & $\mathrm{Z}=-1.71, p=.08$ \\
\hline \multicolumn{4}{|c|}{ Absolute fat mass (kg) } \\
\hline Zumba & $16.69(14.1-33.37,20.16)$ & $16.5(14.32-32.51,19.87)$ & $\mathrm{Z}=-1.81, p=.07$ \\
\hline $\begin{array}{c}\text { Functional } \\
\text { training }\end{array}$ & $18.28(8.8-27.35,17.82)$ & $18.56(9.27-26.65,17.65)$ & $\mathrm{Z}=-1.72, p=.08$ \\
\hline \multicolumn{4}{|c|}{ Fat free mass $(\mathrm{kg})$} \\
\hline Zumba & $48.96(40.52-53.82,48.15)$ & $48.86(40.58-53.48,48.04)$ & $\mathrm{Z}=-0.25, p=.79$ \\
\hline $\begin{array}{c}\text { Functional } \\
\text { training }\end{array}$ & $48.98(39.91-53.64,48.54)$ & $49.13(39.99-53.48,48.55)$ & $\mathrm{Z}=-0.47, p=.63$ \\
\hline \multicolumn{4}{|c|}{ Fat free mass index $(\%)$} \\
\hline Zumba & $17.77(16.72-19.33,17.89)$ & $17.84(16.83-18.96,17.88)$ & $\mathrm{Z}=-0.31, p=.75$ \\
\hline $\begin{array}{c}\text { Functional } \\
\text { training }\end{array}$ & $17.65(14.84-20.69,17.56)$ & $17.61(14.87-20.65,17.56)$ & $\mathrm{Z}=-0.47, p=.64$ \\
\hline
\end{tabular}


Changes in the body image. During the first examination, the real body image did not differ between the groups $(U=116, p=.89)$. During the first examination, the real body image of the Zumba training group was $4(3-6,4.5)$ points, and after the training program $-4(3-5,4.06)$ points. After the Zumba training program, the real body image scores did not differ statistically significantly, however, there was a tendency of score decrease $(Z=-1.81, p=.07)$. During the first examination of functional training group, the real body image was $5(2-6,4.27)$ points, and after the training program $-4(2-5,3.8)$ points. The scores of the real body image in the functional training group decreased statistically significantly $(Z=-2.33 ; p=$ .02) (Figure 1).

Before applying training programs, the ideal body image did not differ between two groups ( $U$ $=120 ; p=1)$. The ideal body image of the Zumba training group was $3(2-4,3.19)$ points, and after the training program $-3(2-4,3)$ points. After Zumba training program, the ideal body image did not change significantly $(Z=-1.34, p=.18)$. The ideal body scores in the functional training group were $3(3-5,3.2)$ points, and after the training program $-3(2-4 ; 3)$ points. The ideal body scores also did not change statistically significantly is this group $(Z=-1, p=.31)$.

The difference between the ideal body image and the real body image did not differ between two groups $(U=84.5, p=.16)$. Before applying Zumba training, the difference between the ideal body image of the participants from the real body image was $3(2-4 ; 2.81)$ points, and after the exercise training $-2.5(2-4,2.63)$ points. The difference between the ideal body image and the real body image was not statistically significantly different in the Zumba training group, but the tendency of decrease the ideal body image difference from the real body image was observed $(Z=-1.73, p=.08)$. The difference between the ideal body image and the real body image during the first examination in the functional training group was $2(1-3,2.33)$ points and in the second examination $-2(1-3,2.27)$ points. The difference between the ideal body image and the real body image did not change statistically significantly in functional training group $(Z=-0.57, p=.56)$.

Before functional and Zumba training, the total body shape questionnaire score did not differ between two groups $(U=116.5, p=.89)$.

The total score for the body shape questionnaire was $35.5(22-66,39.62)$ points in the Zumba training group at the beginning of the study, while during second examination total score was $36(20-55,37.12)$ points. There were no statistically significant changes of body self-dissatisfaction after Zumba training program, only the tendency of total score decrease was observed $(Z=-1.47, p=$ .14). Of all the 16 questions statistically significant

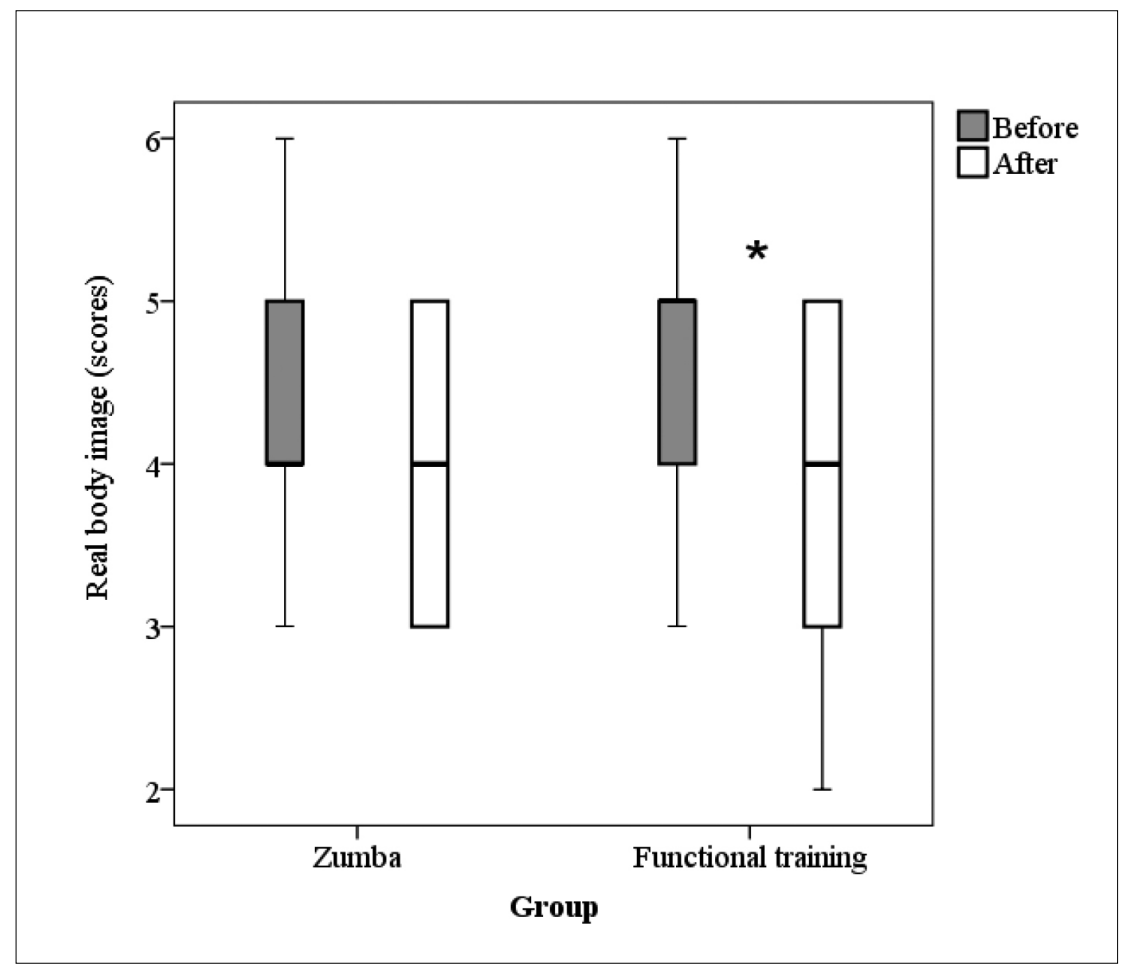

Figure 1. Changes in real body image after Zumba and functional training programs 
Figure 2. Changes in dissatisfaction with body shape after Zumba and functional training programs

Note. $* p<.05$.

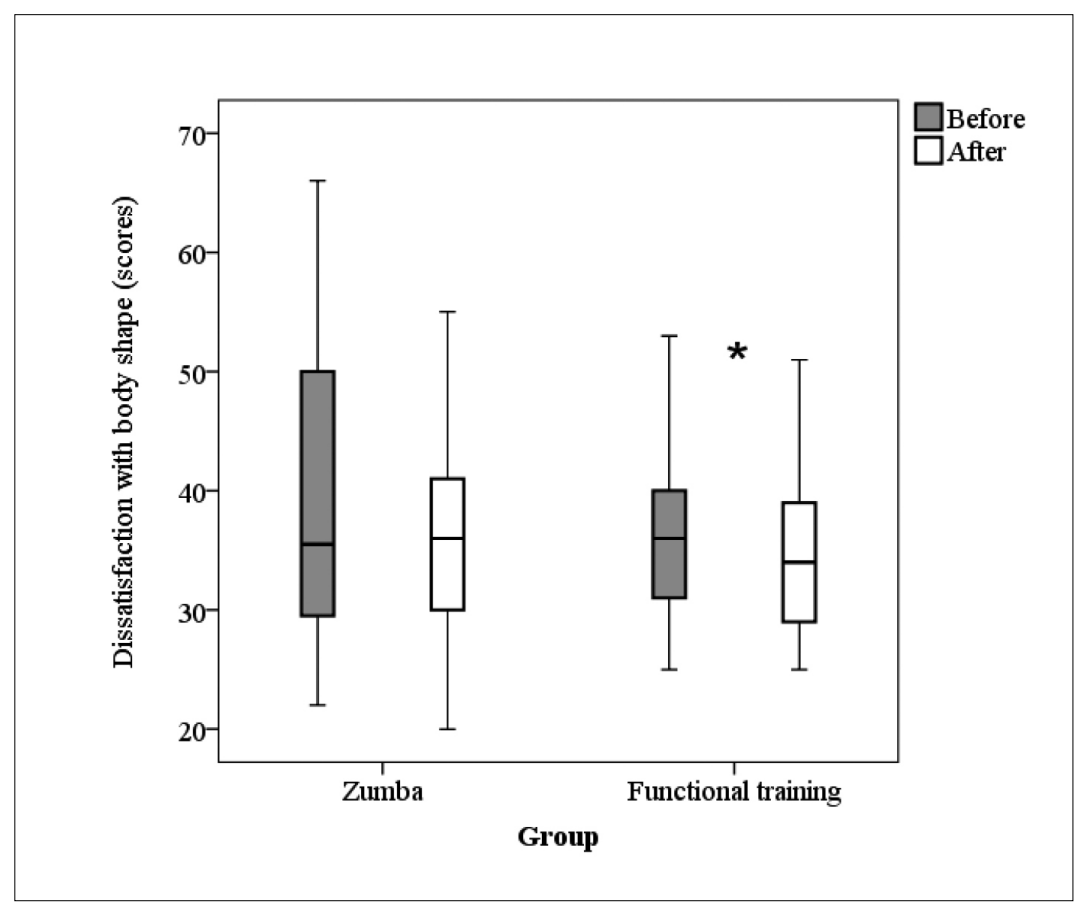

changes were observed in 14th question "Have you felt that it is not fair that other women are thinner than you?" $(Z=-2.53, p=.01)$ and 15 th question "Have you worried about your flesh being dimply?" $(Z=-2.41, p=.02)$.

The total score of the body shape questionnaire during first examination in the functional training group was $36(25-53,37.06)$ points and in the second study $-34(25-51,35.13)$ points. The dissatisfaction with their body statistically significantly reduced after the functional training program $(Z=-2.36$, $p=.02$ ) (Figure 2).

Of all the 16 questions, there was a statistically significant decrease in the 3rd question "Have you worried about your flesh being not firm enough?" scores $(Z=-2.16, p=.03)$ and the 6th question "Has being with thin women made you feel selfconscious about your shape?" scores in functional training group $(Z=-2, p=.04)$.

\section{DISCUSSION}

Analysing the data of our study we found the body weight, percent body fat and absolute body fat decrease tendency in Zumba and functional training groups. Active body mass and active body mass index changes were not found. Ljubojević, Jakovljević, and Popržen (2014) found that eight weeks of Zumba training three times a week statistically significantly reduced body weight, percent body mass and increased lean body mass measurements of young women. Comparing this study to ours, the results may differ because of different training rate. Haghjoo, Zar, and Hoseini's (2016) study showed that eight weeks, three times a week Zumba training reduces women's body mass index, percent fat mass, absolute fat mass and reduces waist - hip ratio, but statistically significant results of fat free mass were not found. We also found no changes in fat free mass measurements, but other results differ from those of Haghjoo et al.s' (2016) investigation findings because of different training rate. Therefore, based on the research we have been discussing, we conclude that after two months of attending Zumba training, body composition changes can be detected by training at least three times a week. Analogous research that studies the effect of functional training on the body composition of women who perform sedentary work cannot be found, but we will discuss studies that compare the effects of aerobic and strength training on body composition measurements since functional training was used in our study, most exercises consisted of strength exercises. Willis et al. (2012) studied aerobics, aerobic-strength and strength training on the body composition of participants who perform sedentary work. Aerobic training and aerobics-strength training were found to be superior to strength training to reduce body weight and percent fat mass, and strength and aerobic-strength exercises are more effective in increasing fat free mass of participants. It has been 
shown that in order to prevent weight gain or to reduce the fat mass, a moderate intensity physical activity of 150-250 minutes should be performed per week, and in order to achieve a clinically meaningful reduction in body weight, moderate intensity physical activity should be performed at 225-420 minutes per week. Performing 150-250 minutes per week of moderate physical activity, clinically relevant changes in the body composition are achieved with nutritional correction (Donnelly et al., 2009). In our research, the participants trained for 120 minutes per week. Based on the studies discussed, we can state that the exposure time we applied was too short or that the frequency of exercise was too rare to achieve statistically significant changes in the body composition. We found statistically significant improvements in the real body image in the functional training group, as well as a significant reduction in body selfdissatisfaction in the functional training group and a decrease tendency of owns body dissatisfaction and a statistically significant reduction in separate question scores in the Zumba group. Other body image changes were not detected. According to scientific literature, physical exercises have a positive effect on general well-being, psychological state, improve mood, quality of life, increase selfesteem and reduce depressive symptoms (Tylka, \& Homan 2015). Although we did not evaluate these changes in our research, we believe that a possible mood or self-efficacy improvement had an impact on the body image results.

Vocks, Hechler, Rohrig, and Legenbauer (2009) found that women who attended physical activity classes felt leaner than they really were. In our study it also occurred: women who trained in the functional training group, considered themselves to be leaner after classes. Women who participated in our study attended the Zumba and functional training groups, i.e. they met and communicated with each other. Communication allows to express emotions and reduce stress and anxiety (Adilogullari, 2014), so we believe that socialization could also have an impact on an improved attitude in their body. The self-body evaluation depends on the motivation for attending workouts. It has been observed that frequent high intensity trainings increase the risk of eating disorders, and women who are attending physical activities with the aim of loss and burning calories are more dissatisfied with their body than those whose purpose of attending workouts is to improve general well-being, not related to slimming (LePage \& Crowther, 2010; Homana \& Tylka, 2014). It is believed, that persons who are not satisfied with their body, experience negative emotions after physical activities more often, i.e. physical activity leads to a more critical evaluation of their body, and those who are positively evaluating their body, experience even better emotions after physical activity (Homana \& Tylka, 2014).

\section{CONCLUSION}

Body composition did not change significantly after eight weeks of Zumba or functional training, however the reduction of body dissatisfaction was found after the functional training program.

\section{REFERENCES}

Abdelaal, M., le Roux, C. W., \& Docherty, N. G. (2017). Morbidity and mortality associated with obesity. Annals of Translational Medicine, 5(7), 161. doi: 10.21037/ atm.2017.03.107

Adilogullari, I. (2014). The examining the effects of 12week Latin dance exercise on social physique anxiety: The effects of 12-week Latin dance. Journal The Anthropologist, 18(2), 421-425. doi: org/10.1080/0972 0073.2014 .11891560

Beckham, S. G., \& Harper, M. (2010). Functional training. Fad or here to stay? ACSM's Health \& Fitness Journal, 14(6), 24-30. doi: 10.13189/saj.2017.050302

Bergman, F., Boraxbekk, C. J., Wennberg, P., Sorlin, A., \& Olsson, T. (2015). Increasing physical activity in office workers-the Inphact Treadmill study: A study protocol for a 13-month randomized controlled trial of treadmill workstations. BMC Public Health, 15, 632. doi: 10.1186/s12889-015-2017-6

Church, T. S., Thomas, D. M., Tudor-Locke, C., Katzmarzyk, P. T., Earnest, C. P., Rodarte, R. Q., ... Bouchard, C. (2011). Trends over 5 decades in U.S. occupation-related physical activity and their associations with obesity. PLoS One, 6(5), e19657. doi: 10.1371/journal.pone.0019657

Cooper, P. J., Taylor, M. J., Cooper Z., Fairbum, Ch. G. (1987). The development and validation of the body shape questionnaire. International Journal of Eating Disorders, 6(4), 485-494. doi: org/10.1002/1098-108X(198707)6:4<485::AIDEAT2260060405>3.0.CO;2-O

Donnelly, J. E., Blair, S. N., Jakicic, J. M., Manore, M. M., Rankin, J. W., \& Smith, B. K. (2009). 
American College of Sports Medicine Position Stand. Appropriate physical activity intervention strategies for weight loss and prevention of weight regain for adults. Medicine and Science in Sports and Exercise, 41(2), 459-471. doi: 10.1249/MSS.0b013e3181949333

Garrusi, B., \& Baneshi, M. R. (2017). Body dissatisfaction among Iranian youth and adults. Cad Saude Publica, 33(9), e00024546. doi: 10.1590/0102311X00024516

Haghjoo, M., Zar, A., \& Hoseini, S. (2016). Effect of 8-week Zumba training on overweight women's body composition. Pars Journal of Medical Sciences, 14(2), 21-29. doi: 10.29252/jmj.14.2.21

Homana, K. J., \& Tylka, T. L. (2014). Appearance-based exercise motivation moderates the relationship between exercise frequency and positive body image. Body Image, 11(2), 101-108. doi: org/10.1016/j.bodyim.2014.01.003 Jackson, A. S., Pollock, M. L., \& Ward, A. (1980). Generalized equations for predicting body density of women. Medicine and Science in Sports and Exercise, 12, 175-182.

Jankauskiene, R., Kardelis, K., \& Pajaujiene, S. (2005). Body weight satisfaction and weight loss attempts in fitness activity involved women. The Journal of Sports Medicine and Physical Fitness, 45(4), 537-545.

Jankauskiene, R., \& Pajaujiene, S. (2012). Disordered eating attitudes and body shame among athletes, exercisers and sedentary female college students. The Journal of Sports Medicine and Physical Fitness, 52(1), 92-101.

Jankauskienè, R., Pajaujienè, S., \& Mickūnienè, R. (2010). Studenčiu siekimo atitikti socialinius išvaizdos lūkesčius ryšys su požiūriu į sveikatai žalingą su valgymu ir fiziniu aktyvumu susijusią elgseną. Visuomenès sveikata, 3(50), 100-109.

LePage, M. L., \& Crowther, J. H. (2010). The effects of exercise on body satisfaction and affect. Body Image, 7(2), 124-130. doi: 10.1016/j.bodyim.2009.12.002

Liu, C., Shiroy, D. M., Jones, L. Y., \& Clark, D. O. (2014). Systematic review of functional training on muscle strength, physical funtioning, and activities of daily life in older adults. European Review of Aging and Physical Activity, 11, 95-106. doi: org/10.1007/s11556014-0144-1

Ljubojević, A., Jakovljević, V., \& Popržen, M. (2014).
Effects of zumba fitness program on body composition of women. SportLogia, 10(1), 29-33.

Luettgen, M., Foster, C., Doberstein, S., Mikat, R., \& Porcari, J. (2012). Zumba((R)): Is the "fitness-party" a good workout? Journal of Sports Science and Medicine, 11(2), 357-358.

Obesity and overweight. (2017, October 18). Retrieved from Word Health Organisation: http://www.who.int/ mediacentre/factsheets/fs311/en/

Pruis, T. A., \& Janowsky, J. S. (2010) Assessment of body image in younger and older women. Journal of General Psychology: Experimental, Psychological, and Comparative Psychology, 137(3), 225-238. doi: 10.1080/00221309.2010.484446

Ribeiro-Silva, R. C., Fiaccone, R. L., ConceicaoMachado, M. E. P. D., Ruiz, A. S., Barreto, M. L., \& Santana, M. L. P. (2017). Body image dissatisfaction and dietary patterns according to nutritional status in adolescents. Jornal de Pediatria (Rio J) (16), 155-161. doi: 10.1016/j.jped.2017.05.005

Sakalauskaite, E., \& Tutkuvienè, J. (2009). Kūno įvaizdis: veiksniai ir sąsajos su fizine būkle. Laboratorine medicina, 4(44), 215-222.

Tylka, T. L., \& Homan, K. J. (2015). Exercise motives and positive body image in physically active college women and men: Exploring an expanded acceptance model of intuitive eating. Body Image, 15, 90-97. doi: 10.1016/j.bodyim.2015.07.003

Vocks, S., Hechler, T., Rohrig, S., \& Legenbauer, T. (2009). Effects of a physical exercise session on state body image: The influence of pre-experimental body dissatisfaction and concerns about weight and shape. Psychology \& Health, 24(6), 713-728. doi: 10.1080/08870440801998988

Williams, E. P., Mesidor, M., Winters, K., Dubbert, P. M., \& Wyatt, S. B. (2015). Overweight and obesity: Prevalence, consequences, and causes of a growing public health problem. Current Obesity Reports, 4(3), 363-370. doi: 10.1007/s13679-015-0169-4

Willis, L. H., Slentz, C. A., Bateman, L. A., Shields, T. A., Piner, W., Bales, C. W., ... Kraus, W. E. (2012). Effects of aerobic and/or resistance training on body mass and fat mass in overweight or obese adults. Journal of Applied Physiology, 113(12), 1831-1837. doi: 10.1152/ japplphysiol.01370.2011 